Published in final edited form as:

Hepatology. 2013 June ; 57(6): 2338-2345. doi:10.1002/hep.26264.

\title{
Soluble receptor for advanced glycation end products and risk of liver cancer
}

\author{
Kristin A. Moy ${ }^{1}$, Li Jiao², Neal D. Freedman ${ }^{1}$, Stephanie J. Weinstein ${ }^{1}$, Rashmi Sinha ${ }^{1}$, \\ Jarmo Virtamo ${ }^{3}$, Demetrius Albanes ${ }^{1}$, and Rachael Z. Stolzenberg-Solomon ${ }^{1}$ \\ ${ }^{1}$ Division of Cancer Epidemiology and Genetics, National Cancer Institute, Nation Institutes of \\ Health, Bethesda, Maryland ${ }^{2}$ Section of Gastroenterology and Hepatology, Department of \\ Medicine, Baylor College of Medicine, Houston, TX ${ }^{3}$ Department of Chronic Disease Prevention, \\ National Institute for Health and Welfare, Helsinki, Finland
}

\begin{abstract}
Binding of advanced glycation end products (AGEs) to their receptor (RAGE) increases oxidative stress and inflammation, and may be involved in liver injury and subsequent carcinogenesis. Soluble RAGE (sRAGE) may neutralize the effects mediated by AGEs/RAGE complex. Epidemiologic studies examining sRAGE or AGEs in association with liver cancer are lacking. We examined the associations between prediagnostic serum concentrations of sRAGE or $\mathrm{Ne}$ (carboxymethyl)-lysine (CML)-AGE and hepatocellular carcinoma (HCC) in a case-cohort study within a cohort of 29,133 Finnish male smokers who completed questionnaires and provided a fasting blood sample in 1985-1988. During follow-up beginning 5 years after enrollment through April 2006, 145 liver cancers occurred. Serum concentrations of sRAGE, CML-AGE, glucose, and insulin were measured in cases and 485 randomly sampled cohort participants. Chronic hepatitis $B$ virus (HBV) and hepatitis $\mathrm{C}$ virus (HCV) were available on most cases and a subset of the study population. Weighted Cox proportional hazards regression was used to calculate relative risks (RR) and 95\% confidence intervals (CI), adjusted for age, years of smoking, and body mass index. sRAGE and CML-AGE concentrations were inversely associated with liver cancer (sRAGE: RR, highest versus lowest tertile, $0.77 ; 95 \% \mathrm{CI}, 0.48-1.24 ; P_{\text {trend }}=0.28$; continuous RR, 0.86; 95\% CI, 0.75-0.99; CML-AGE: RR, highest versus lowest tertile, 0.19; 95\% CI, 0.10-0.35; $P_{\text {trend }}<0.0001$; continuous RR, 0.74; 95\% CI, 0.65-0.84). Further adjustment for glucose and insulin, or exclusion of cases with chronic $\mathrm{HBV}$ or $\mathrm{HCV}$, did not change the associations.
\end{abstract}

Conclusion-Our results support the hypothesis that sRAGE is inversely associated with liver cancer. The findings need confirmation, particularly in populations that include women and nonsmokers.

\section{Keywords}

sRAGE; CML-AGE; case-cohort; incidence; men

\begin{abstract}
Worldwide, primary liver cancer is the sixth most commonly occurring cancer and the third most common cause of cancer-related deaths $(1,2)$. Established risk factors for hepatocellular carcinoma or HCC, the most common type, include aflatoxin B exposure, chronic infection with hepatitis B (HBV) or hepatitis C (HCV), excessive alcohol consumption, and obesity and diabetes which increase the risk of nonalcoholic
\end{abstract}

Correspondance: Kristin A. Moy, PhD, MPH, Postdoctoral Fellow, Nutritional Epidemiology Branch, Division of Cancer Epidemiology and Genetics, 6120 Executive Blvd., Suite 320, Rockville, MD 20852, P: 301-496-5700, moyka@mail.nih.gov. 
steatohepatitis (NASH) $(3,4)$. These risk factors are typified by their ability to cause chronic inflammation in the liver which is associated with subsequent carcinogenesis (5). Advanced glycation end products (AGE) and their receptor (RAGE) are implicated in both inflammation and cancer (reviewed (6-8)). However, the potential role of the AGE-RAGE axis in the development of HCC is unknown.

AGEs are group of heterogeneous irreversible adducts formed by the non-enzymatic glycation of proteins, lipids and nucleic acids (7). The two major sources of AGEs are endogenous AGEs that form during normal metabolism and exogenous AGEs derived from tobacco smoke or food $(7,9)$. Dietary AGEs are formed when food is processed at high temperatures using methods such as deep frying, broiling and grilling (10). AGEs accumulate in tissues and the rate of accumulation increases with aging and under hyperglycemic conditions (7). Of the approximately 20 different AGEs identified, $N^{\varepsilon}$ (carboxymethyl)-lysine (CML-AGE) is the best characterized $(11,12)$.

AGEs upregulate inflammation through binding their full-length membrane bound receptor, RAGE $(7,13)$. RAGE is a multiligand receptor that belongs to the immunoglobulin superfamily. Binding ligand triggers the activation of cell signaling pathways such as p38 and $\mathrm{p} 44 / 42$ MAP kinase, as well as NF- $\kappa \mathrm{B}$, generating reactive oxygen species and the production of proinflammatory cytokines (reviewed $(6,14)$ ). As the liver is important for the clearance and catabolism of circulating AGEs [e.g., removing more than $90 \%$ of intravenously injected AGEs via endocytosis has been shown in rats $(13,15)]$, the AGERAGE axis may be particularly important for liver carcinogenesis and chronic liver diseases including NASH and liver cirrhosis (16-18).

In addition to the full-length receptor for AGEs, RAGE has truncated soluble isoforms (sRAGE) containing only the RAGE extracellular domain $(13,15)$, including a splice variant of the full-length receptor, endogenous secretory RAGE, and an isoform formed by proteolytic cleavage $(19,20)$. Both forms can be detected in human serum, are capable of binding ligands, and thought to bind free AGEs, exerting a cytoprotective effect by preventing ligands from binding to cell surface $\operatorname{RAGE}(8,15)$. In vitro and experimental studies suggest a protective role of sRAGE in hepatocellular injury (21-27).

Although several hospital-based studies have found sRAGE levels to be lower in lung, breast and pancreatic cancer cases compared to healthy controls (28-30), only three prospective epidemiologic studies have examined the potential association of AGEs with cancer finding no significant associations between CML-AGE and pancreatic $(31,32)$ or colorectal cancers (33). In the current study, we examined the associations of serum levels of sRAGE and CML-AGE with liver cancer risk in the Alpha-Tocopherol, Beta-Carotene Cancer Prevention (ATBC) Study (34). We hypothesized that lower levels of sRAGE or higher levels of CML-AGE are associated with increased risk.

\section{Materials and Methods}

\section{Study population}

The design of the ATBC Study has been described in detail elsewhere (34). Briefly, the ATBC Study was a randomized, double-blind, placebo-controlled, primary prevention trial conducted in southwest Finland to determine the effects of supplementation with atochopherol and $\beta$-carotene on cancer incidence among male smokers. Between 1985 and 1988 , a total of 29,133 Caucasian men aged 50 to 69 years who smoked at least 5 cigarettes per day were randomized to receive an active supplement or a placebo. Potential participants were excluded from the trial if they reported malignancy other than nonmelanoma skin cancer or carcinoma in situ, severe angina on exertion, chronic renal insufficiency, cirrhosis 
of liver, chronic alcoholism, receiving anticoagulant therapy, other medical problems that might limit participation for 6 years or reported current use of supplements containing vitamin E, vitamin A or $\beta$-carotene in excess of predefined doses (34). The trial ended in April 1993 but participants continued to be followed for health outcomes through national registries. The ATBC Study was approved by the institutional review boards of both the US National Cancer Institute and the National Public Health Institute of Finland (now National Institute for Health and Welfare, Helsinki, Finland). All participants provided written informed consent before randomization.

At enrollment, participants completed a self-administered questionnaire that assessed demographics, medical, smoking and occupational histories. Dietary intake during the previous year was also assessed using a validated self-administered dietary history questionnaire. Height and weight were measured by trained nurses. Body mass index (BMI) was calculated as (weight in kilograms)/(height in meters, squared) (34). Study participants also provided venous blood samples after an overnight fast at baseline, and serum was aliquoted and stored at $-70^{\circ} \mathrm{C}$.

\section{Cases and subcohort}

The present study is a case-cohort study within the parent study. To reduce to the potential effect of subclinical disease on serum levels of CML-AGE or sRAGE in samples collected at baseline prior to randomization, subjects in this study were drawn from cohort members who were alive and cancer-free as of the sixth year of follow-up $(\mathrm{N}=24,708)(34)$. Thus, follow-up began 5 years after blood collection at randomization and ended at date of liver cancer diagnosis, death or on April 30, 2006, whichever occurred earlier. A total of 146 incident liver cancer cases (defined based on the International Classification of Diseases 9; codes 155.0, 155.1, and 155.2) were identified from the Finish Cancer Registry (35). From remaining eligible cohort members, 500 subjects were randomly selected as the reference group. After excluding 1 case and 15 subcohort participants with missing data on one or more of the serological biomarkers, the present analysis included 145 liver cancer cases and 485 subcohort participants.

\section{Laboratory methods}

Serum sRAGE and CML-AGE were measured in duplicate by Microcoat Biotechnologie Company using the human sRAGE Quantikine ELISA kit (r\&D system Inc.) and the AGECML-ELISA kit (Microcoat Biotechnologie Company), respectively. The AGE-CMLELISA kit uses a CML-specific monocolonal antibody (mouse monocolonal 4G9; Alteon Inc) (36). The sRAGE Quantikine kit detects a heterogeneous group of total sRAGE proteins, including cleavage forms of membrane-bound full-length RAGE (19), endogenous secretory RAGE (20), and other splice variant forms of RAGE. Cases and subcohort samples were randomly ordered in each batch along with $10 \%$ blinded quality control (QC) samples from a single pooled serum sample. The intrabatch coefficients of variation for sRAGE and CML-AGE were $3 \%$ and $7 \%$, respectively and the corresponding interbatch coefficients of variation were $6 \%$ and $14 \%$. Serum concentrations of glucose and insulin were previously measured for 51 cases and 406 subcohort participants (37). In the present study, serum glucose and insulin were determined on an additional 95 cases that occurred after 2001 and on an additional 94 subcohort participants using the same method in the same laboratory as the earlier study.

\section{Statistical analysis}

The Wilcoxon rank sum test for continuous variables and the $\chi^{2}$ test for categorical variables were used to compare the distributions of selected demographics, dietary and other characteristics between the cases and the subcohort. Dietary variables were adjusted for total 
energy intake using the residuals method (38). Selected demographic and dietary variables were examined across tertiles of serum CML-AGE and sRAGE using the analysis of covariance method.

Standard statistical methods for case-cohort studies were used in the present study. Weighted Cox proportional hazards regression was used to calculate relative risks (RR) and their corresponding 95\% confidence intervals (CIs) and $P$-values (39). Study subjects were grouped by tertiles of sRAGE and CML-AGE defined according to the distribution in the subcohort. Continuous RRs were calculated to the average size of the central tertile to represent the change in risk of liver cancer per tertile and p-values for linear trends across tertiles were performed using a score variable based on the median value of each tertile. Follow-up time was used as the underlying time metric. We used forward and backward stepwise regression to evaluate potential confounding. Factors evaluated as potential confounders of the sRAGE or CML-AGE and liver cancer associations include the variables listed in Table 1. A variable was defined as a confounding factor if it was significantly associated with liver cancer risk and SRAGE or CML-AGE, and inclusion of the variable in the model changed the risk estimate for sRAGE or CML-AGE by more than 10\%. Although none of the variables (Table 1) met the latter criterion, final multivariate models included age at randomization, years of smoking and BMI. Further adjustment for number of cigarettes per day, trial treatment arm or other variables associated with sRAGE or CMLAGE (Table 2) did not change risk estimates more than $10 \%$ and were not included in the final models. To assess whether the associations between sRAGE or CML-AGE and liver cancer were independent of other serum analytes, insulin and glucose concentration were added into the models individually, but as their inclusion did not change the risk estimates more than $10 \%$, they were not retained in the final models.

Effect modification of sRAGE and CML-AGE by BMI (continuous and $<25 \mathrm{~kg} / \mathrm{m}^{2}$ versus $\geq 25 \mathrm{~kg} / \mathrm{m}^{2}$ ), number of years of smoking (continuous), number of cigarettes per day (continuous), serum glucose (continuous), clinical diabetes (yes or no), energy-adjusted red meat intake (continuous), coffee intake (continuous) and trial intervention (placebo, $\beta$ carotene only, $a$-tocopherol only, $\beta$-carotene plus $\alpha$-tocopherol) was tested by including cross-product terms in multivariate models and testing for statistical significance using the Wald test. Additionally, the joint effects of sRAGE and CML-AGE (both dichotomous) on the risk of liver cancer were examined. To examine potential differential effects of sRAGE and CML-AGE at different stages of liver carcinogenesis, we examined the associations between sRAGE or CML-AGE and liver cancer stratified by follow-up time (subjects with 5 to 9 years of follow-up and subjects with 10+ years of follow-up).

Exposure to hepatitis B (HBV) and hepatitis C (HCV) infection serologic status was available for 135 cases and 26 subcohort subjects in the present study. Sensitivity analyses excluding participants who were positive for hepatitis B core antigen (anti-HBc), hepatitis B surface antigen (HBsAg) or hepatitis $\mathrm{C}$ (anti-HCV) were conducted. Statistical analysis was carried out using SAS software version 9.1 (SAS Institute, Cary, NC) and SUDAAN software (RTI, Research Triangle Park, NC). All statistical tests were 2-sided and $P$-values less than 0.05 were considered to be statistically significant.

\section{Results}

In the present study, the average time ( \pm standard deviation) between serum collection and liver cancer diagnosis was $12.2( \pm 4.2)$ years, ranging from 5 to 21 years. The mean age $( \pm$ standard deviation) at liver cancer diagnosis was $70.3( \pm 5.4)$ years. 
Compared to subcohort participants, liver cancer cases were slightly older at time of randomization, had a higher BMI and reported smoking more cigarettes per day for a longer period of time (Table 1). Cases were also more likely to report having been diagnosed with diabetes, and consuming more red meat and alcohol. Cases also consumed less coffee, saturated fat and carbohydrates than their subcohort counterparts. Cases had significantly lower serum levels of CML-AGE and borderline significantly lower serum levels of sRAGE compared to the subcohort population (Table 1).

Table 2 shows the age-adjusted means of selected baseline characteristics associated with liver cancer or AGEs of the subcohort participants according to tertiles of serum sRAGE and CML-AGE. There was higher carbohydrate and sucrose intake across tertiles of sRAGE ( $P$ values $\$$ D.01). With increasing tertiles of CML-AGE, mean BMI, and total and saturated fat intake were significantly lower (all $P$-values $\$ 0.004$ ), whereas intake of carbohydrate, glucose, sucrose and iron all were significantly higher (all $P$-values $\unlhd \mathbf{0} .04$ ).

Serum sRAGE concentrations were associated with a statistically significant reduction in risk of liver cancer when examined as a continuous variable (RR, 0.86; 95\% CI, $0.75-0.99$, $P=0.02$ ) and non-significant reduced risk comparing the highest to lowest tertile (RR, 0.77; 95\% CI, 0.48 - 1.24; $P$ for trend, 0.28) (Table 3). Higher CML-AGE concentrations were significantly associated with reduced risk of liver cancer when examined as a continuous variable standardized to the central tertile (RR, $0.74 ; 95 \% \mathrm{CI}, 0.65-0.84, P<0.0001)$ and in a dose-dependent manner when examined categorically (T3 versus T1, RR, 0.19; 95\% CI, $0.10-0.35 ; P$ for trend $<0.0001$ ). Further adjustment for serum glucose and insulin or trial intervention did not materially change theses associations (data not shown).

There was no evidence of effect modification of the sRAGE or CML-AGE and liver cancer associations by BMI, smoking duration and intensity, serum glucose, diabetes, or intake of energy-adjusted red meat, alcohol, coffee or by trial intervention arm (all $P$-values for interaction were greater than 0.10$)$, nor the joint effect of serum sRAGE and CML-AGE $(P$ for interaction $=0.34$ ). We stratified the associations by follow-up time (subjects with 5 to 9 years of follow-up and subjects with 10+ years of follow-up, based on 52 and 93 cases, respectively) and observed no evidence that the associations differed by time from blood collection to diagnosis (all $P$ for interactions $>0.14$, data not shown).

As part of another nested case-control study on liver cancer within the ATBC cohort, information on hepatitis B and C titers were measured. Within that study, the prevalence of hepatitis B surface antigen (HBsAg) was $1.2 \%$ among liver cancer cases (2/167) and 0.7\% among controls (6/817) while the prevalence of hepatitis B core antigen (anti-HBc) was $15 \%$ among cases (25/167) and 7\% among controls (57/817) and the prevalence of hepatitis C exposure (anti-HCV) was 5\% among cases (8/167) and $0.6 \%(5 / 817)$ among controls (personal communication Neal Freedman). In the present study, 135 cases and 26 subcohort members had hepatitis B and C information. Only 1 subcohort member and 18 cases tested positive for anti-HBc and 1 case and 0 subcohort members were positive for $\mathrm{HBsAg}$. Similarly, 4 cases and 2 subcohort members were positive for anti-HCV. As hepatitis infection is an important risk factor for liver cancer, though clearly not in our study population, we repeated the analyses after excluding the 19 cases and 2 subcohort members who tested positive for $\mathrm{HBsAg}$, anti-HBc or anti-HCV, and the associations did not change.

\section{Discussion}

In our prospective study of male Finnish smokers with a low prevalence of chronic HBV and HCV infections, serum levels of sRAGE were associated with a modest reduction in risk of liver cancer. A borderline statistically significant inverse association between continuous 
sRAGE and liver cancer risk suggests that the soluble receptor of AGEs may protect against the inflammatory effects caused by RAGE activation. We also observed an unexpected, highly statistically significant, inverse association between serum CML-AGE and liver cancer.

Experimental studies suggest the critical role of RAGE activation in liver injury and furthermore, indicate that blocking RAGE may mitigate liver injury. For example, in a mouse model of total heptatic ischemia/reperfusion, blockade of RAGE with sRAGE administered via intraperitoneal injections improved survival, protected against hepatocellular necrosis, and enhanced expression of pro-regenerative cytokine tumor necrosis factor-a (TNF-a) (27). In another study, blockade of RAGE with sRAGE attenuated liver injury caused by toxic doses of acetaminophen and a similar increase in proregenerative cytokines TNF- $a$ and iterleukin- 6 was observed (24). These and other rodent models [reviewed in (15)] support the role of RAGE in liver fibrosis and that blocking RAGE activation may prevent the progression of liver fibrosis, indirectly preventing liver carcinogenesis.

Several human studies have investigated the potential roles of RAGE and SRAGE in inflammation. In the only study that includes HCC, expression of RAGE mRNA is lower in normal liver than in chronic hepatitis and is the highest in HCC, suggesting RAGE activation may be involved in HCC etiology (16); this study, however, is cross-sectional and temporality cannot be determined. In a second study, patients with NASH had significantly lower circulating levels of sRAGE compared to healthy controls with normal liver function tests and liver sonograms (26). Obese Caucasian prepubertal children with nonalcoholic fatty liver disease also had significantly lower sRAGE levels compared to obese but otherwise healthy children (40). As NASH may precede liver cancer, our observed borderline statistically significant, inverse association between serum sRAGE and liver cancer is in line with these previous studies. Together, these results suggest that sRAGE may act as a decoy receptor, binding free AGEs and other RAGE ligands, and perhaps mitigating the effects of RAGE activation in the liver.

As CML-AGE is one of the most abundant AGEs and binds readily with full-length RAGE, we hypothesized that higher serum levels of CML-AGE would be associated with increased risk of liver cancer. Instead, we observed an inverse association. Explanations for these results are unclear. Serum CML-AGE may not be the optimal marker of AGEs or RAGE activation in the liver as CML-AGE is only one of many RAGE ligands. For example, high mobility group box-1 (HMGB1) is another ligand of RAGE that activates the proinflammatory cell signaling cascade and plays a critical role in the mechanisms leading to liver injury $(6,8,15,41)$. One possible explanation for our observed inverse association is confounding, if levels of CML-AGE were associated with another liver cancer risk factor. For example, we and others (42) have shown CML-AGE to be inversely associated with body fat in older adults and preferentially deposited in fat tissues. It is possible that the inverse association that we observe between CML-AGE and liver cancer might be explained by body fat. Adjustments for body mass index did not affect our results, however, BMI is only an imperfect proxy for body fat deposition, particularly in the liver.

As with all studies, the present investigation has limitations. First, the study findings in Finnish male smokers may not be generalizable to other populations that include women and nonsmokers. Nevertheless, the modest inverse association between serum sRAGE and liver cancer is both biologically plausible and in line with laboratory and limited clinical data. Although the ATBC study population is Finnish male smokers, previously observed associations in this population have been replicated in populations that include women and non-smokers $(43,44)$. The present study also did not examine other AGEs beside CML- 
AGE which may limit our ability to tease out the true role of total AGEs in RAGE activation and subsequent liver cancer etiology. Other RAGE ligands that were not measured in this study, such as HMGB1, which may be associated with liver cancer risk. The use of a single measurement of biomarkers at only one point in time may not characterize long-term concentrations, whereas repeated measurements within subjects over time may provide a more accurate assessment of exposure. However, it is rarely feasible to assess multiple time points due to the high cost and logistical complexity of collecting biospecimens from a large number of participants in a cohort study. Although the single, pre-diagnostic measurements of sRAGE and CML-AGE limits our ability to draw conclusions of the role the AGE-RAGE axis on the etiology of liver cancer, our study is the first to examine sRAGE and CML-AGE in association with incident liver cancer. Strengths of our study include the prospective nature and the availability of fasting blood samples collected at least 5 years before the diagnosis of liver cancer, and the long follow-up, which reduces the possibility of reverse causality in the present study; however, we note that chronic liver disease progression and carcinogenesis can occur over a very long period of time and we lacked information on preexisting liver disease at baseline. The low prevalence of $\mathrm{HBV}$ and $\mathrm{HCV}$ in our population (14\% among cases) diminishes the possibility that $\mathrm{HBV} / \mathrm{HCV}$ status, the primary risk factors of liver cancer in other populations, may confound our results. Moreover, when we performed sensitivity analyses excluding the few subjects positive for chronic infection of $\mathrm{HBV}$ and HCV, the associations between serum CML-AGE or sRAGE and liver cancer did not change. Finland is known to have among the lowest prevalence of HBV and HCV in the world. In the general population of Finland, the prevalence of HBV and HCV are $0.2 \%$ and $<2 \%$, respectively (45) which is similar to that of the ATBC study.

In conclusion, the findings from our prospective study among Finnish male smokers support the hypothesis that sRAGE may be protective against liver cancer. Our results, particularly the unexpected inverse association observed with serum levels of CML-AGE warrant examination in other populations.

\section{Acknowledgments}

Grant Support:

This research was supported by the Intramural Research Program of the National Institutes of Health, Division of Cancer Epidemiology and Genetics, National Cancer Institute, National Institutes of Health, Department of Health and Human Services.

\section{Abbreviations}

$\begin{array}{ll}\text { AGE } & \text { advanced glycation end product } \\ \text { RAGE } & \text { receptor for advanced glycation end product } \\ \text { SRAGE } & \text { soluble receptor for advanced glycation end product } \\ \text { CML-AGE } & \text { Ne-(carboxymethyl)-lysine-AGE } \\ \text { HBV } & \text { hepatitis B virus } \\ \text { HCV } & \text { hepatitis C virus } \\ \text { RR } & \text { relative risks } \\ \text { CI } & \text { confidence interval } \\ \text { HCC } & \text { hepatocellular carcinoma } \\ \text { NASH } & \text { nonalcoholic steatohepatitis }\end{array}$




$\begin{array}{ll}\text { ATBC } & \text { Alpha-Tocopherol, Beta-Carotene Cancer Prevention Study } \\ \text { BMI } & \text { body mass index } \\ \text { TNF-a } & \text { tumor necrosis factor-a } \\ \text { HMGB1 } & \text { high mobility group box-1 }\end{array}$

\section{References}

1. Bosch FX, Ribes J, Diaz M, Cleries R. Primary liver cancer: worldwide incidence and trends. Gastroenterology. 2004; 127:S5-S16. [PubMed: 15508102]

2. Siegel R, Naishadham D, Jemal A. Cancer statistics, 2012. CA Cancer J Clin. 2012; 62:10-29. [PubMed: 22237781]

3. Alkofer B, Lepennec V, Chiche L. Hepatocellular cancer in the non-cirrhotic liver. J Visc Surg. 2011; 148:3-11. [PubMed: 21306970]

4. McGlynn KA, London WT. The global epidemiology of hepatocellular carcinoma: present and future. Clin Liver Dis. 2011; 15:223-243. vii-x. [PubMed: 21689610]

5. El-Serag HB, Rudolph KL. Hepatocellular carcinoma: epidemiology and molecular carcinogenesis. Gastroenterology. 2007; 132:2557-2576. [PubMed: 17570226]

6. Riehl A, Nemeth J, Angel P, Hess J. The receptor RAGE: Bridging inflammation and cancer. Cell Commun Signal. 2009; 7:12. [PubMed: 19426472]

7. Singh R, Barden A, Mori T, Beilin L. Advanced glycation end-products: a review. Diabetologia. 2001; 44:129-146. [PubMed: 11270668]

8. Sparvero LJ, Asafu-Adjei D, Kang R, Tang D, Amin N, Im J, Rutledge R, et al. RAGE (Receptor for Advanced Glycation Endproducts), RAGE ligands, and their role in cancer and inflammation. $\mathrm{J}$ Transl Med. 2009; 7:17. [PubMed: 19292913]

9. Abe R, Yamagishi S. AGE-RAGE system and carcinogenesis. Curr Pharm Des. 2008; 14:940-945. [PubMed: 18473843]

10. Uribarri J, Woodruff S, Goodman S, Cai W, Chen X, Pyzik R, Yong A, et al. Advanced glycation end products in foods and a practical guide to their reduction in the diet. J Am Diet Assoc. 2010; 110:911-916. e912. [PubMed: 20497781]

11. Semba RD, Nicklett EJ, Ferrucci L. Does accumulation of advanced glycation end products contribute to the aging phenotype? J Gerontol A Biol Sci Med Sci. 2010; 65:963-975. [PubMed: 20478906]

12. Semba RD, Ang A, Talegawkar S, Crasto C, Dalal M, Jardack P, Traber MG, et al. Dietary intake associated with serum versus urinary carboxymethyl-lysine, a major advanced glycation end product, in adults: the Energetics Study. Eur J Clin Nutr. 2012; 66:3-9. [PubMed: 21792213]

13. Hyogo H, Yamagishi S. Advanced glycation end products (AGEs) and their involvement in liver disease. Curr Pharm Des. 2008; 14:969-972. [PubMed: 18473847]

14. Bierhaus A, Nawroth PP. Multiple levels of regulation determine the role of the receptor for AGE (RAGE) as common soil in inflammation, immune responses and diabetes mellitus and its complications. Diabetologia. 2009; 52:2251-2263. [PubMed: 19636529]

15. Basta G, Navarra T, De Simone P, Del Turco S, Gastaldelli A, Filipponi F. What is the role of the receptor for advanced glycation end products-ligand axis in liver injury? Liver Transpl. 2011; 17:633-640. [PubMed: 21438128]

16. Hiwatashi K, Ueno S, Abeyama K, Kubo F, Sakoda M, Maruyama I, Hamanoue M, et al. A novel function of the receptor for advanced glycation end-products (RAGE) in association with tumorigenesis and tumor differentiation of HCC. Ann Surg Oncol. 2008; 15:923-933. [PubMed: 18080716]

17. Yagmur E, Tacke F, Weiss C, Lahme B, Manns MP, Kiefer P, Trautwein C, et al. Elevation of Nepsilon-(carboxymethyl)lysine-modified advanced glycation end products in chronic liver disease is an indicator of liver cirrhosis. Clin Biochem. 2006; 39:39-45. [PubMed: 16321365] 
18. Hyogo H, Yamagishi S, Iwamoto K, Arihiro K, Takeuchi M, Sato T, Ochi H, et al. Elevated levels of serum advanced glycation end products in patients with non-alcoholic steatohepatitis. $\mathrm{J}$ Gastroenterol Hepatol. 2007; 22:1112-1119. [PubMed: 17559366]

19. Raucci A, Cugusi S, Antonelli A, Barabino SM, Monti L, Bierhaus A, Reiss K, et al. A soluble form of the receptor for advanced glycation endproducts (RAGE) is produced by proteolytic cleavage of the membrane-bound form by the sheddase a disintegrin and metalloprotease 10 (ADAM10). FASEB J. 2008; 22:3716-3727. [PubMed: 18603587]

20. Yonekura H, Yamamoto Y, Sakurai S, Petrova RG, Abedin MJ, Li H, Yasui K, et al. Novel splice variants of the receptor for advanced glycation end-products expressed in human vascular endothelial cells and pericytes, and their putative roles in diabetes-induced vascular injury. Biochem J. 2003; 370:1097-1109. [PubMed: 12495433]

21. Butscheid M, Schafer C, Brenner S, Alscher D, Murdter T, Niwa T, Frischmann M, et al. Unchanged serum levels of advanced glycation endproducts in patients with liver disease. Naunyn Schmiedebergs Arch Pharmacol. 2007; 375:401-406. [PubMed: 17571253]

22. Butscheid M, Hauptvogel P, Fritz P, Klotz U, Alscher DM. Hepatic expression of galectin-3 and receptor for advanced glycation end products in patients with liver disease. J Clin Pathol. 2007; 60:415-418. [PubMed: 16775125]

23. Cataldegirmen G, Zeng S, Feirt N, Ippagunta N, Dun H, Qu W, Lu Y, et al. RAGE limits regeneration after massive liver injury by coordinated suppression of TNF-alpha and NF-kappaB. J Exp Med. 2005; 201:473-484. [PubMed: 15699076]

24. Ekong U, Zeng S, Dun H, Feirt N, Guo J, Ippagunta N, Guarrera JV, et al. Blockade of the receptor for advanced glycation end products attenuates acetaminophen-induced hepatotoxicity in mice. J Gastroenterol Hepatol. 2006; 21:682-688. [PubMed: 16677153]

25. Sebekova K, Kupcova V, Schinzel R, Heidland A. Markedly elevated levels of plasma advanced glycation end products in patients with liver cirrhosis - amelioration by liver transplantation. $\mathrm{J}$ Hepatol. 2002; 36:66-71. [PubMed: 11804666]

26. Yilmaz Y, Ulukaya E, Gul OO, Arabul M, Gul CB, Atug O, Oral AY, et al. Decreased plasma levels of soluble receptor for advanced glycation endproducts (sRAGE) in patients with nonalcoholic fatty liver disease. Clin Biochem. 2009; 42:802-807. [PubMed: 19217891]

27. Zeng S, Feirt N, Goldstein M, Guarrera J, Ippagunta N, Ekong U, Dun H, et al. Blockade of receptor for advanced glycation end product (RAGE) attenuates ischemia and reperfusion injury to the liver in mice. Hepatology. 2004; 39:422-432. [PubMed: 14767995]

28. Tesarova P, Kalousova M, Jachymova M, Mestek O, Petruzelka L, Zima T. Receptor for advanced glycation end products (RAGE)--soluble form (sRAGE) and gene polymorphisms in patients with breast cancer. Cancer Invest. 2007; 25:720-725. [PubMed: 18058469]

29. Krechler T, Jachymova M, Mestek O, Zak A, Zima T, Kalousova M. Soluble receptor for advanced glycation end-products (sRAGE) and polymorphisms of RAGE and glyoxalase I genes in patients with pancreas cancer. Clin Biochem. 2010; 43:882-886. [PubMed: 20398646]

30. Jing R, Cui M, Wang J, Wang H. Receptor for advanced glycation end products (RAGE) soluble form (sRAGE): a new biomarker for lung cancer. Neoplasma. 2010; 57:55-61. [PubMed: 19895173]

31. Grote VA, Nieters A, Kaaks R, Tjonneland A, Roswall N, Overvad K, Nielsen MR, et al. The Associations of Advanced Glycation End Products and Its Soluble Receptor with Pancreatic Cancer Risk: A Case-Control Study within the Prospective EPIC Cohort. Cancer Epidemiol Biomarkers Prev. 2012; 21:619-628. [PubMed: 22301828]

32. Jiao L, Weinstein SJ, Albanes D, Taylor PR, Graubard BI, Virtamo J, Stolzenberg-Solomon RZ. Evidence that serum levels of the soluble receptor for advanced glycation end products are inversely associated with pancreatic cancer risk: a prospective study. Cancer Res. 2011; 71:35823589. [PubMed: 21540233]

33. Jiao L, Taylor PR, Weinstein SJ, Graubard BI, Virtamo J, Albanes D, Stolzenberg-Solomon RZ. Advanced glycation end products, soluble receptor for advanced glycation end products, and risk of colorectal cancer. Cancer Epidemiol Biomarkers Prev. 2011; 20:1430-1438. [PubMed: 21527578] 
34. The alpha-tocopherol, beta-carotene lung cancer prevention study: design, methods, participant characteristics, and compliance. The ATBC Cancer Prevention Study Group. Ann Epidemiol. 1994; 4:1-10. [PubMed: 8205268]

35. Korhonen P, Malila N, Pukkala E, Teppo L, Albanes D, Virtamo J. The Finnish Cancer Registry as follow-up source of a large trial cohort--accuracy and delay. Acta Oncol. 2002; 41:381-388. [PubMed: 12234031]

36. Boehm BO, Schilling S, Rosinger S, Lang GE, Lang GK, Kientsch-Engel R, Stahl P. Elevated serum levels of N(epsilon)-carboxymethyl-lysine, an advanced glycation end product, are associated with proliferative diabetic retinopathy and macular oedema. Diabetologia. 2004; 47:1376-1379. [PubMed: 15258735]

37. Limburg PJ, Stolzenberg-Solomon RZ, Vierkant RA, Roberts K, Sellers TA, Taylor PR, Virtamo J, et al. Insulin, glucose, insulin resistance, and incident colorectal cancer in male smokers. Clin Gastroenterol Hepatol. 2006; 4:1514-1521. [PubMed: 17162243]

38. Hu FB, Stampfer MJ, Rimm E, Ascherio A, Rosner BA, Spiegelman D, Willett WC. Dietary fat and coronary heart disease: a comparison of approaches for adjusting for total energy intake and modeling repeated dietary measurements. Am J Epidemiol. 1999; 149:531-540. [PubMed: 10084242]

39. Kulathinal S, Karvanen J, Saarela O, Kuulasmaa K. Case-cohort design in practice - experiences from the MORGAM Project. Epidemiol Perspect Innov. 2007; 4:15. [PubMed: 18053196]

40. D'Adamo E, Giannini C, Chiavaroli V, de Giorgis T, Verrotti A, Chiarelli F, Mohn A. What is the significance of soluble and endogenous secretory receptor for advanced glycation end products in liver steatosis in obese prepubertal children? Antioxid Redox Signal. 2011; 14:1167-1172. [PubMed: 20969485]

41. Albayrak A, Uyanik MH, Cerrah S, Altas S, Dursun H, Demir M, Uslu H. Is HMGB1 a new indirect marker for revealing fibrosis in chronic hepatitis and a new therapeutic target in treatment? Viral Immunol. 2010; 23:633-638. [PubMed: 21142449]

42. Semba RD, Arab L, Sun K, Nicklett EJ, Ferrucci L. Fat mass is inversely associated with serum carboxymethyl-lysine, an advanced glycation end product, in adults. J Nutr. 2011; 141:1726-1730. [PubMed: 21775524]

43. Stolzenberg-Solomon RZ, Pietinen P, Taylor PR, Virtamo J, Albanes D. Prospective study of diet and pancreatic cancer in male smokers. Am J Epidemiol. 2002; 155:783-792. [PubMed: 11978580]

44. Thiebaut AC, Jiao L, Silverman DT, Cross AJ, Thompson FE, Subar AF, Hollenbeck AR, et al. Dietary fatty acids and pancreatic cancer in the NIH-AARP diet and health study. J Natl Cancer Inst. 2009; 101:1001-1011. [PubMed: 19561318]

45. Global surveillance and control of hepatitis C. Report of a WHO Consultation organized in collaboration with the Viral Hepatitis Prevention Board, Antwerp, Belgium. J Viral Hepat. 1999; 6:35-47. [PubMed: 10847128] 
Table 1

Baseline characteristics of liver cancer cases and subcohort participants, ATBC Study, 1985-2006

\begin{tabular}{|c|c|c|c|}
\hline Characteristic & Liver cancer cases (n=145) & Subcohort $(\mathrm{n}=\mathbf{4 8 5})$ & $P$-values ${ }^{a}$ \\
\hline Age, mean (sd) & $58.1(4.8)$ & $56.4(5.0)$ & 0.0001 \\
\hline BMI $\left(\mathrm{kg} / \mathrm{m}^{2}\right)$, mean $(s d)$ & $27.6(4.7)$ & $26.7(4.0)$ & 0.03 \\
\hline Years of smoking, mean (sd) & $37.2(8.3)$ & $35.2(8.2)$ & 0.0002 \\
\hline No. cigarettes / day, mean (sd) & $21.5(9.3)$ & $20.8(8.5)$ & 0.50 \\
\hline \multicolumn{4}{|l|}{ Clinical diabetes } \\
\hline Glucose <126 mg/dL, $n(\%)$ & $125(86.2)$ & $461(95.0)$ & 0.0002 \\
\hline Glucose $\geq 126 \mathrm{mg} / \mathrm{dL}, n(\%)$ & $20(13.8)$ & $24(5.0)$ & \\
\hline \multicolumn{4}{|l|}{ Dietary or nutrient intake/day $b$} \\
\hline Total meat $(\mathrm{g})$, mean $(s d)$ & $197(73.3)$ & $194(68.8)$ & 0.65 \\
\hline Red meat $(\mathrm{g})$, mean $(s d)$ & $73.1(30.0)$ & $68.2(28.2)$ & 0.06 \\
\hline Processed meat $(\mathrm{g})$, mean $(s d)$ & $69.4(46.4)$ & $74.3(52.4)$ & 0.59 \\
\hline Alcohol (g), mean (sd) & $27.7(33.1)$ & $18.9(21.7)$ & 0.01 \\
\hline Coffee $(\mathrm{g})$, mean $(s d)$ & $502(337)$ & $595(354)$ & 0.002 \\
\hline Total fat $(\mathrm{g})$, mean $(s d)$ & $119(22.0)$ & $122(18.0)$ & 0.28 \\
\hline Saturated fat $(\mathrm{g})$, mean $(s d)$ & $48.9(15.0)$ & $52.8(13.9)$ & 0.01 \\
\hline Protein $(\mathrm{g})$, mean $(s d)$ & $92.3(13.2)$ & $94.4(12.7)$ & 0.14 \\
\hline Carbohydrates (g), mean (sd) & $257(38.5)$ & $264(39.1)$ & 0.03 \\
\hline Glucose $(\mathrm{g})$, mean $(s d)$ & $8.69(4.37)$ & $9.30(5.76)$ & 0.69 \\
\hline Sucrose $(\mathrm{g})$, mean $(s d)$ & $48.9(26.1)$ & $51.5(24.1)$ & 0.15 \\
\hline Iron $(\mathrm{mg})$, mean $(s d)$ & $17.6(3.87)$ & $17.9(3.43)$ & 0.29 \\
\hline \multicolumn{4}{|l|}{ sRAGE } \\
\hline Mean (sd) & $561(262)$ & $615(307)$ & 0.09 \\
\hline Median (IQR) & $520(377-706)$ & $571(413-738)$ & \\
\hline \multicolumn{4}{|l|}{ CML-AGE } \\
\hline Mean (sd) & 484 (131) & $565(168)$ & $<0.0001$ \\
\hline Median (IQR) & $480(404-680)$ & $561(471-668)$ & \\
\hline \multicolumn{4}{|l|}{ Treatment Arm } \\
\hline Placebo & $35(24.1)$ & $110(22.7)$ & 0.48 \\
\hline BC only & $40(27.6)$ & $116(23.9)$ & \\
\hline AT only & $33(22.8)$ & $131(27.0)$ & \\
\hline $\mathrm{AT}+\mathrm{BC}$ & $37(25.5)$ & $128(26.4)$ & \\
\hline
\end{tabular}

${ }^{a}$ Two-sided $P$-values are based on Wilcoxon rank sum tests for continuous variables and $\chi^{2}$ tests for categorical variables 
Table 2

Selected age-adjusted baseline of characteristics by tertiles of sRAGE and CML-AGE in the subcohort, ATBC Study, 1985-2006

\begin{tabular}{|c|c|c|c|c|}
\hline \multirow[b]{2}{*}{ Characteristic } & \multicolumn{3}{|c|}{ SRAGE } & \multirow[b]{2}{*}{$P_{\text {trend }}$} \\
\hline & Tertile 1 & Tertile 2 & Tertile 3 & \\
\hline Age at randomization ${ }^{a}$ & 56.5 & 56.2 & 56.5 & 0.97 \\
\hline $\operatorname{BMI}\left(\mathrm{kg} / \mathrm{m}^{2}\right) b$ & 27.1 & 26.7 & 26.4 & 0.12 \\
\hline Years of smoking $b$ & 35.2 & 35.6 & 34.7 & 0.57 \\
\hline No. of cigarettes/d & 21.5 & 20.8 & 20.0 & 0.09 \\
\hline Total meat $(\mathrm{g} / \mathrm{d}) b, c$ & 196.7 & 193.9 & 190.5 & 0.42 \\
\hline Red meat $(\mathrm{g} / \mathrm{d}) b, c$ & 67.7 & 68.0 & 68.9 & 0.71 \\
\hline Processed meat $(\mathrm{g} / \mathrm{d}) b, c$ & 77.4 & 75.1 & 70.1 & 0.22 \\
\hline Alcohol (g/d) $b, c$ & 19.9 & 20.1 & 16.6 & 0.30 \\
\hline Coffee $(\mathrm{g} / \mathrm{d}) b, c$ & 590.0 & 567.3 & 629.8 & 0.33 \\
\hline Total fat $(\mathrm{g} / \mathrm{d}) b, c$ & 123.4 & 122.3 & 120.4 & 0.15 \\
\hline Saturated fat $(\mathrm{g} / \mathrm{d}) b, c$ & 53.1 & 52.5 & 52.8 & 0.86 \\
\hline Carbohydrates $(\mathrm{g} / \mathrm{d}) b, c$ & 258.7 & 262.1 & 271.0 & 0.006 \\
\hline Glucose intake $(\mathrm{g} / \mathrm{d}) b, c$ & 8.9 & 9.4 & 9.6 & 0.27 \\
\hline Sucrose intake $(\mathrm{g} / \mathrm{d}) b, c$ & 48.4 & 51.1 & 55.3 & 0.01 \\
\hline $\operatorname{Iron}(\mathrm{mg} / \mathrm{d}) b, c$ & 18.0 & 17.2 & 18.3 & 0.46 \\
\hline Serum insulin $(\mu \mathrm{U} / \mathrm{mL}) b, c$ & 5.2 & 5.2 & 5.0 & 0.75 \\
\hline \multirow[t]{3}{*}{ Serum glucose $(\mathrm{mg} / \mathrm{dL}) b, c$} & 102.7 & 97.5 & 98.0 & 0.10 \\
\hline & \multicolumn{3}{|c|}{ CML-AGE } & \\
\hline & Tertile 1 & Tertile 2 & Tertile 3 & $P_{\text {trend }}$ \\
\hline Age at randomization ${ }^{a}$ & 56.8 & 55.8 & 56.6 & 0.74 \\
\hline $\operatorname{BMI}\left(\mathrm{kg} / \mathrm{m}^{2}\right) b$ & 27.3 & 26.9 & 26.0 & 0.004 \\
\hline Years of smoking $b$ & 35.3 & 35.5 & 34.8 & 0.50 \\
\hline No. of cigarettes/d & 21.1 & 20.4 & 10.7 & 0.70 \\
\hline Total meat $(\mathrm{g} / \mathrm{d}) b, c$ & 193.5 & 189.8 & 197.9 & 0.57 \\
\hline Red meat $(\mathrm{g} / \mathrm{d}) b, c$ & 69.6 & 66.6 & 68.3 & 0.70 \\
\hline Processed meat (g/d) $b, c$ & 75.6 & 73.1 & 74.2 & 0.82 \\
\hline Alcohol (g/d) $b, c$ & 18.5 & 18.7 & 19.5 & 0.67 \\
\hline Coffee $(\mathrm{g} / \mathrm{d}) b, c$ & 566.7 & 636.3 & 582.7 & 0.69 \\
\hline Total fat $(\mathrm{g} / \mathrm{d}) b, c$ & 126.1 & 122.0 & 118.0 & $<0.0001$ \\
\hline Saturated fat $(\mathrm{g} / \mathrm{d}) b, c$ & 55.5 & 53.4 & 49.5 & 0.0001 \\
\hline Carbohydrates $(\mathrm{g} / \mathrm{d}) b, c$ & 255.2 & 263.2 & 273.1 & $<0.0001$ \\
\hline
\end{tabular}




\begin{tabular}{|c|c|c|c|c|}
\hline \multirow[b]{2}{*}{ Characteristic } & \multicolumn{3}{|c|}{ SRAGE } & \multirow[b]{2}{*}{$P_{\text {trend }}$} \\
\hline & Tertile 1 & Tertile 2 & Tertile 3 & \\
\hline Glucose intake (g/d) $b, c$ & 8.3 & 8.6 & 11.0 & $<0.0001$ \\
\hline Sucrose intake (g/d) $b, c$ & 48.7 & 51.7 & 54.2 & 0.04 \\
\hline $\operatorname{Iron}(\mathrm{mg} / \mathrm{d}) b, c$ & 17.6 & 18.0 & 18.4 & 0.04 \\
\hline Serum insulin $(\mu \mathrm{U} / \mathrm{mL}) b, c$ & 5.5 & 5.0 & 4.8 & 0.12 \\
\hline Serum glucose $(\mathrm{mg} / \mathrm{dL}) b, c$ & 99.6 & 97.3 & 101.4 & 0.50 \\
\hline \multicolumn{5}{|l|}{${ }^{a}$ Unadjusted } \\
\hline
\end{tabular}


